\title{
Perencanaan Struktur Atap RS Bhayangkara Polda Jambi Dengan Mempergunakan Profil Baja IWF
}

\author{
Doni Prayogi, M. Asmuni Jatoeb* , M. Nuklirullah \\ Teknik Sipil Universitas Batanghari \\ *Correspondence email: asmunijatoeb@gmail.com
}

\begin{abstract}
Abstrak. Baja banyak digunakan sebagai bahan konstruksi karena memiliki keunggulan dibandingkan bahan beton dan kayu, selain itu bentuk dan ukuran baja yang bervariasi memudahkan baja untuk digunakan dalam banyak konstruksi-konstruksi bangunan. Seperti pada tugas akhir ini yaitu perencanaan atap rumah sakit Bhayangkara Polda Jambi menggunakan struktur baja. Lokasi studi berada di Jl. Raden Mattaher, Kelurahan Rajawali, Kecamatan Jambi Timur, Kota Jambi, rumah sakit ini adalah milik dari polri yang pembangunannya dimulai pada tahun 2018. Pada lantai atas rumah sakit tersebut nantinya akan dibuat kantin, oleh karena itu pada lantai atas akan direncanakan struktur atap dengan menggunakan baja IWF. Pemilihan material baja IWF dikarenakan struktur yang direncanakan memiliki bentang yang lebar dan mudah diaplikasikan pada bangunan rumah sakit serta pengerjaannya yang cepat karena struktur berbentuk portal tanpa sistem rangka. Metode desain dalam perencanaan tugas akhir ini menggunakan Desain Faktor Beban dan Ketahanan (DFBK). Pada perencanaan ini didapat gording menggunakan profil kanal $100 \times 50 \times 20 \times 4 \mathrm{~mm}$. Ikatan angin dan trackstang masing-masing menggunakan besi $12 \mathrm{~mm}$. Balok dan kolom menggunakan profil IWF $350 \times 350 \times 12 \times 19 \mathrm{~mm}$. Sambungan konstruksi menggunakan sambungan baut dan las. Sambungan balok dengan kolom menggunakan 10 baut $\emptyset 22 \mathrm{~mm}$ dan las ukuran $8 \mathrm{~mm}$ dengan panjang $160 \mathrm{~mm}$. Sambungan balok dengan balok menggunakan 8 baut $\emptyset 16 \mathrm{~mm}$ dan las ukuran $8 \mathrm{~mm}$ dengan panjang $90 \mathrm{~mm}$. Sambungan base-plate menggunakan 6 baut angkur $\emptyset 19 \mathrm{~mm}$ dan las ukuran $5 \mathrm{~mm}$ dengan panjang $310 \mathrm{~mm}$.
\end{abstract}

Kata kunci :Struktur atap, Baja IWF, DFBK

\section{PENDAHULUAN}

Dunia konstruksi pada saat sekarang ini berkembang sangat pesat. Untuk membangun suatu konstruksi bangunan memerlukan bahan atau material yang baik dan sesuai dengan kebutuhan, salah satu material konstruksi adalah baja. Baja adalah salah satu bahan material yang digunakan untuk material konstruksi dari jenis logam yang memiliki sifat sangat keras.

Baja banyak digunakan sebagai bahan konstruksi karena memiliki keunggulan dibandingkan bahan beton dan kayu. Konstruksi baja bukan hanya digunakan untuk bangunan sederhana tetapi untuk bangunan-bangunan yang besar, seperti pembuatan struktur atap untuk gedung kantor, gedung rumah sakit dan bangunan yang memiliki bentang relatif panjang. Seperti pada tugas akhir ini yaitu perencanaan atap rumah sakit Bhayangkara Polda Jambi menggunakan struktur baja. Lokasi studi berada di Jl. Raden Mattaher, Kelurahan Rajawali, Kecamatan Jambi Timur, Kota Jambi, rumah sakit ini adalah milik dari polri yang pembangunannya dimulai pada tahun 2018. Pada lantai atas rumah sakit tersebut nantinya akan dibuat kantin, oleh karena itu pada lantai atas akan direncanakan struktur atap dengan menggunakan baja IWF. Pemilihan material baja IWF dikarenakan struktur yang direncanakan memiliki bentang yang lebar dan mudah diaplikasikan pada bangunan rumah sakit serta pengerjaannya yang cepat karena struktur berbentuk portal tanpa sistem rangka. Metode desain dalam perencanaan tugas akhir ini menggunakan Desain Faktor Beban dan Ketahanan (DFBK), metode DFBK memiliki kelebihan dari pada metode Desain Kekuatan Izin (DKI) karena metode DFBK pada perhitungan desain material dikali dengan faktor ketahan sehingga dari perencanaan material bisa memikul beban sesuai dengan batas tegangannya dan menghasilkan perencanaan yang lebih baik dan efisien.

Tujuan dari penulisan tugas akhir ini adalah untuk merencanakan struktur atap menggunakan material baja yang akan diterapkan pada gedung rumah sakit Bhayangkara Polda Jambi. Adapun manfaat dari studi tugas akhir ini adalah Menambah wawasan bagi penulis mengenai perencanaan struktur atap rangka baja menggunakan profil IWF dan Menambah referensi bagi pembaca tentang perencanaan struktur atap rangka baja dengan profil IWF yang baik.

Kekuatan baja tergantung dari mutu yang dimiliki oleh baja. Seberapa tinggi mutu yang dimiliki baja dapat diketahui dari sifat mekanis baja (BJ). BJ baja memiliki dua variabel yaitu $F_{y}$ dan $F_{u}$, dimana $F_{y}$ menyatakan kekuatan tegangan tekan lelehnya, sedangkan $F_{u}$ menyatakan batas maksimum tegangan putus. Mutu baja memiliki satuan MPa (Megapascal) yaitu satuan internasional. 
Tabel 1. Sifat Mekanis Baja Struktural

\begin{tabular}{|c|c|c|c|}
\hline Jenis Baja & $\begin{array}{c}\text { Tegangan Putus } \\
\text { Minimum } \\
F_{u}(\mathrm{MPa})\end{array}$ & $\begin{array}{c}\text { Tegangan Leleh Minimum } \\
F_{y}(\mathrm{MPa})\end{array}$ & $\begin{array}{c}\text { Regangan } \\
\text { Minimum } \\
(\%)\end{array}$ \\
\hline BJ 34 & 340 & 210 & 22 \\
BJ 37 & 370 & 240 & 20 \\
BJ 41 & 410 & 250 & 18 \\
BJ 50 & 500 & 290 & 16 \\
BJ 55 & 550 & 410 & 13 \\
\hline
\end{tabular}

Sumber : Agus Setiawan, 2008

\section{Kombinasi Beban}

Kombinasi beban adalah analisa beban-beban yang bekerja pada suatu konstruksi dan kemudian dihitung dengan cara mengkombinasikan beban-beban tersebut hingga didapatkan hasil yang paling tidak baik di dalam konstruksi tersebut. Menurut SNI 1727:2013 Beban minimum untuk perencanaan bangunan gedung dan struktur lain, pada kombinasi beban nominal yang menggunakan metode desain faktor beban dan ketahanan (DFBK). Kombinasi beban yang digunakan sesuai SNI 1727:2013 pasal 2.3.2 sebagai berikut:

$1,4 \mathrm{D}$

$1,2 \mathrm{D}+1,6\left(\mathrm{~L}_{\mathrm{r}}\right.$ atau $\mathrm{S}$ atau $\left.\mathrm{R}\right)+(\mathrm{L}$ atau $0,5 \mathrm{~W})$

dimana :
Pers. 1

Pers. 2

$$
\begin{array}{ll}
\mathrm{D} & =\text { Beban mati } \\
\mathrm{W} & =\text { Beban angin } \\
\mathrm{L} & =\text { Beban hidup } \\
\mathrm{L}_{\mathrm{r}} & =\text { Beban hidup atap } \\
\mathrm{R} & =\text { Beban air hujan }
\end{array}
$$

\section{Tekuk torsi lateral}

$\mathrm{M}_{\mathrm{p}}=Z_{X} \times F_{y}$

Pers. 3

$Z_{X}=b_{f} \times t_{f}\left(\mathrm{~d}-t_{f}\right)+0,25 t_{w} h^{2}$

Pers. 4

dimana :

$\mathrm{M}_{\mathrm{p}} \quad=$ momen plastis, N.mm

$b_{f} \quad=$ lebar sayap profil, $\mathrm{mm}$

$Z_{X} \quad=$ nilai absolut statis momen, $\mathrm{mm}^{3}$

$\mathrm{d}=$ tinggi profil, $\mathrm{mm}$

$t_{f} \quad=$ tebal sayap profil, $\mathrm{mm}$

$t_{w} \quad=$ tebal badan profil, $\mathrm{mm}$

$F_{y} \quad=$ tegangan leleh mutu baja, $\mathrm{MPa}$

$\mathrm{h} \quad=$ tinggi pelat badan profil, $\mathrm{mm}$

$$
\mathrm{C}_{\mathrm{b}}=\frac{12,5\left|\mathrm{M}_{\text {max }}\right|}{2,5\left|\mathrm{M}_{\text {max }}\right|+3\left|\mathrm{M}_{\mathrm{A}}\right|+4\left|\mathrm{M}_{\mathrm{B}}\right|+3\left|\mathrm{M}_{\mathrm{C}}\right|}
$$

Pers. 5

Dimana :

Momen $\max =$ momen terbesar

$M_{A} \quad=$ Momen di $1 / 4$ panjang balok $M_{A}$

$M_{B} \quad=$ Momen di $1 / 2$ panjang balok $M_{B}$

$M_{C} \quad=$ Momen di $3 / 4$ panjang balok $M_{C}$

$\mathrm{F}_{\mathrm{cr}}=\frac{\mathrm{C}_{\mathrm{b}} \pi^{\mathrm{a}} \mathrm{E}}{\left(\frac{\mathrm{L}_{\mathrm{b}}}{\mathrm{r}_{\mathrm{tg}}}\right)^{2}} \sqrt{1+0,078 \frac{\mathrm{I}_{\mathrm{c}}}{\mathrm{S}_{\mathrm{Xh}}\left(\frac{\mathrm{L}_{\mathrm{b}}}{\mathrm{r}_{\mathrm{ts}}}\right)^{2}}}$

Pers. 6

dimana : 
$\mathrm{E}=$ modulus elastis baja $=29000 \mathrm{ksi}(200000 \mathrm{MPa})$

$\mathrm{J} \quad=$ konstanta torsi, in..$^{4}\left(\mathrm{~mm}^{4}\right)$

$\mathrm{S}_{\mathrm{x}} \quad=$ modulus penampang elastis di sumbu $\mathrm{x}$, in. ${ }^{3}\left(\mathrm{~mm}^{3}\right)$

$\mathrm{h}_{\mathrm{o}} \quad=$ jarak antar titik berat sayap, in. $(\mathrm{mm})$

$\mathrm{Mn}=\mathrm{C}_{\mathrm{b}}\left[\mathrm{Mp}-(\mathrm{Mp}-0,7 \mathrm{Fy} \mathrm{Sx})\left(\frac{\mathrm{Lb}-\mathrm{Lp}}{\mathrm{Lr}-\mathrm{Lp}}\right)\right] \leq \mathrm{Mp}$

Pers. 7

dimana :

Fy $\quad=$ tegangan leleh profil MPa

$\mathrm{S}_{\mathrm{x}} \quad=$ modulus elastisitas penampang terhadap sumbu kuat, $\mathrm{mm}^{3}$

$\mathrm{L}_{\mathrm{b}} \quad$ = panjang antara titik-titik, baik yang dibreising melawan perpindahan lateral sayap tekan atau dibreising melawan puntir penampang melintang, in. ( $\mathrm{mm})$

$\mathrm{L}_{\mathrm{p}}=1,76 \mathrm{r}_{\mathrm{y}} \sqrt{\frac{E}{F_{y}}}$

Pers. 8

dimana :

$\mathrm{E} \quad=$ modulus elastisitas baja $=200.000,00 \mathrm{MPa}$

$\mathrm{F}_{\mathrm{y}} \quad=$ kuat leleh minimum, tergantung mutu baja, $\mathrm{MPa}$

$\mathrm{r}_{\mathrm{y}} \quad=$ radius girasi balok terhadap sumbu lemah

$\mathrm{L}_{\mathrm{r}}=1,95 \mathrm{r}_{\mathrm{ts}} \frac{E}{0,7 F_{y}} \sqrt{\frac{\mathrm{Jc}}{\mathrm{S}_{\mathrm{X}} \mathrm{h}_{\mathrm{o}}}+\sqrt{\left(\frac{\mathrm{Jc}}{\mathrm{S}_{\mathrm{x}} \mathrm{h}_{\mathrm{o}}}\right)^{2}+6,76\left(\frac{0,7 \mathrm{~F}_{\mathrm{y}}}{\mathrm{E}}\right)^{2}}}$

Pers. 9

Dimana :

$\mathrm{J}=$ konstanta torsi, $\mathrm{mm}^{4}$

$\mathrm{S}_{\mathrm{x}} \quad=$ modulus elastisitas penampang terhadap sumbu kuat, $\mathrm{mm}^{3}$

$\mathrm{h}_{\mathrm{o}} \quad=$ jarak antar titik berat elemen sayap, $\mathrm{mm}$

$\mathrm{r}^{2} \mathrm{ts}=\frac{\sqrt{\mathrm{I}_{\mathrm{y}} \mathrm{C}_{\mathrm{W}}}}{\mathrm{S}_{\mathrm{X}}}$

Pers. 10

dan koefisien c ditentukan sebagai berikut:

(a) Untuk profil I simetri ganda: $\mathrm{c}=1$

(b) Untuk profil I nilai $\mathrm{C}_{\mathrm{w}}=\frac{1}{4} \mathrm{I}_{\mathrm{y}} \mathrm{h}_{\mathrm{o}}^{2}$

$\mathrm{r}_{\mathrm{ts}}^{2}=\frac{1}{2} \mathrm{I}_{\mathrm{y}} \mathrm{h}_{\mathrm{o}} / \mathrm{S}_{\mathrm{x}}$

Pers. 11

Dimana :

$\mathrm{I}_{\mathrm{y}} \quad=$ momen inersia sumbu lemah profil $\mathrm{mm}^{4}$

$\mathrm{S}_{\mathrm{x}} \quad=$ modulus elastisitas penampang terhadap sumbu kuat, $\mathrm{mm}^{3}$

$\mathrm{h}_{\mathrm{o}} \quad=$ jarak antar titik berat elemen sayap, $\mathrm{mm}$

\section{Kuat Lentur Nominal}

$\mathrm{M}_{\mathrm{u}} \leq \phi_{\mathrm{L}} \mathrm{M}_{\mathrm{n}}$

(DFBK)

Pers. 12

Dimana :

$\mathrm{M}_{\mathrm{u}} \quad$ = Kuat lentur atau momen maksimum hasil kombinasi beban

$\phi_{\mathrm{L}} \quad=$ Faktor ketahanan lentur, sebesar 0,9

$\mathrm{M}_{\mathrm{n}} \quad$ = Kuat lentur nominal balok

\section{Interaksi Gaya Aksial Dan Momen Lentur}

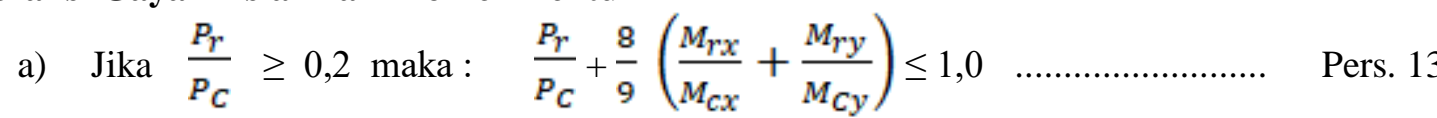




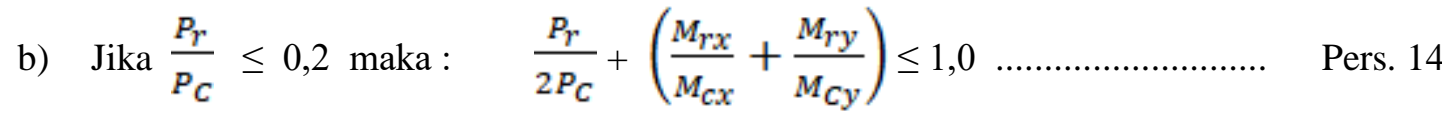
dimana :

$P_{r} \quad=P_{U}$ kuat aksial perlu elemen struktur

$P_{C} \quad=\phi P_{n}$ kuat tekan nominal rencana elemen struktur

$M_{r} \quad=M_{U}$ kuat lentur perlu elemen

$M_{C} \quad=\phi M_{n}$ kuat rencanan elemen struktur sebagai balok lentur

$\mathrm{x} \quad=$ subskrip simbol untuk momen lentur terhadap sumbu kuat penampang

$\mathrm{y} \quad=$ subskrip simbol untuk momen lentur terhadap sumbu lemah penampang

\section{Interaksi Gaya Geser Dan Momen Lentur}

$\frac{M_{U}}{\phi M_{n}}+0,625\left(\frac{V_{U}}{\phi V_{n}}\right)<1,375$

Pers. 15

dimana :

$M_{U} \quad=$ kuat lentur perlu elemen

$\phi M_{n} \quad=$ kuat rencanan elemen struktur sebagai balok lentur

$V_{U} \quad=$ kuat geser perlu elemen

$\phi V_{n} \quad=$ kuat geser nominal rencana elemen struktur

Kuat baut angkur terhadap geser

$\phi_{\mathrm{ag}} \mathrm{V}_{\mathrm{sa}}=\phi_{\mathrm{ag}} 0.60 \mathrm{~A}_{\mathrm{se}}, \mathrm{v} f_{\text {wta }}$

Pers. 16

dimana :

$\mathrm{V}_{\mathrm{sa}} \quad=$ kuat geser nominal baut angkur

$\phi_{\mathrm{ag}} \quad=$ faktor reduksi kuat baut angkur terhadap geser $=0,65$

$\mathrm{A}_{\mathrm{se}, \mathrm{V}} \quad=$ luas penampang efektif terhadap geser

$n_{t} \quad=$ jumlah ulir per mm (atau ulir per inch)

$\mathrm{Pa} \quad=$ pitch, mm per ulir (atau inch per ulir)

$f_{u t a}=$ Kuat tarik baut angkur yang disyaratkan, tidak lebih dari nilai terkecil $1,9 f_{y a}$ atau $860 \mathrm{MPa}$

Kuat baut angkur terhadap tarik

$\phi_{\mathrm{sa}} N_{s a} \geq \phi_{\mathrm{sa}} A_{S E_{\mathrm{r}} N} \times f_{\mathrm{wta}}$

Pers. 17

dimana:

$N_{s a} \quad=$ kuat tarik nominal baut angkur

$\phi_{\mathrm{sa}} \quad=$ faktor reduksi kuat baut angkur terhadap tarik $=0,75$

$A_{S E_{s} N} \quad=$ luas penampang efektif terhadap tarik

$\mathrm{n}_{\mathrm{t}} \quad=$ jumlah ulir per mm (atau ulir per inch)

$\mathrm{Pa}=$ pitch, $\mathrm{mm}$ per ulir (atau inch per ulir)

Interaksi gaya tarik dan geser baut angkur

$\frac{\mathrm{N}_{\mathrm{ua}}}{\phi_{s a} \mathrm{~N}_{\mathrm{U}}}+\frac{\mathrm{V}_{\mathrm{ua}}}{\phi_{a g} \mathrm{~V}_{\mathrm{n}}} \leq 1,2$

Pers. 18

dimana:

$\mathrm{N}_{\text {ua }} \quad$ = gaya aksial maksimum kolom

$\mathrm{V}_{\mathrm{ua}} \quad=$ gaya geser maksimum kolom

$\phi_{\mathrm{sa}} \mathrm{N}_{\mathrm{U}}=$ kuat baut angkur terhadap tarik

$\phi_{\mathrm{ag}} \mathrm{V}_{\mathrm{n}}=$ kuat baut angkur terhadap geser 


\section{METODE}

Sumber : Hasil Analisa 2020

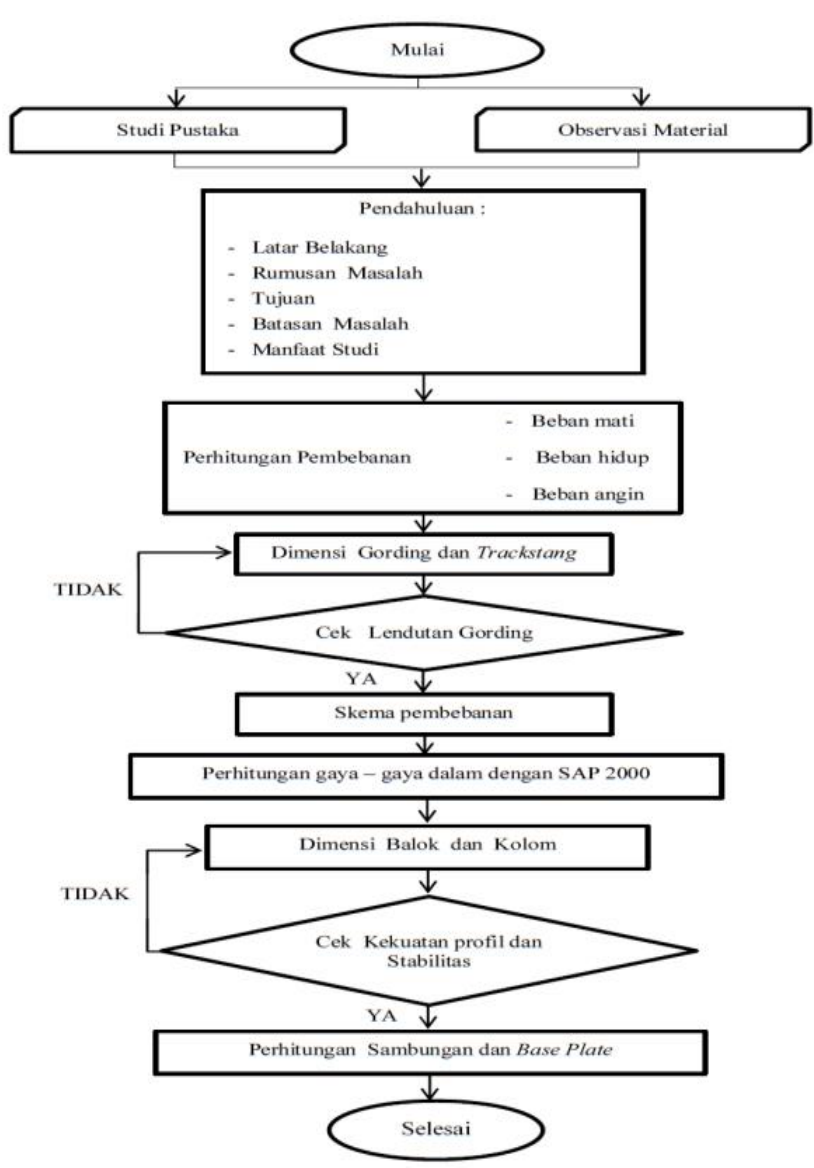

Gambar 1. Bagan alir penulisan tugas akhir

\section{HASIL DAN PEMBAHASAN}

Adapun data-data yang digunakan dalam perencanaan sebagai berikut:

a) Jarak kolom / Jarak kuda - kuda (Lk) $=4$ meter

b) Tinggi kolom (Tk) $\quad=5$ meter

c) Bentang kuda - kuda (Lt) $\quad=30$ meter

d) Kemiringan sudut atap $\quad=15^{0}$

e) Bahan atap (Ba) = Metal zincalume $\left(6 \mathrm{Kg} / \mathrm{m}^{2}\right)$

f) Alat sambung = Baut dan Las

g) Mutu Baja = BJ 37

h) Trackstang =2 buah

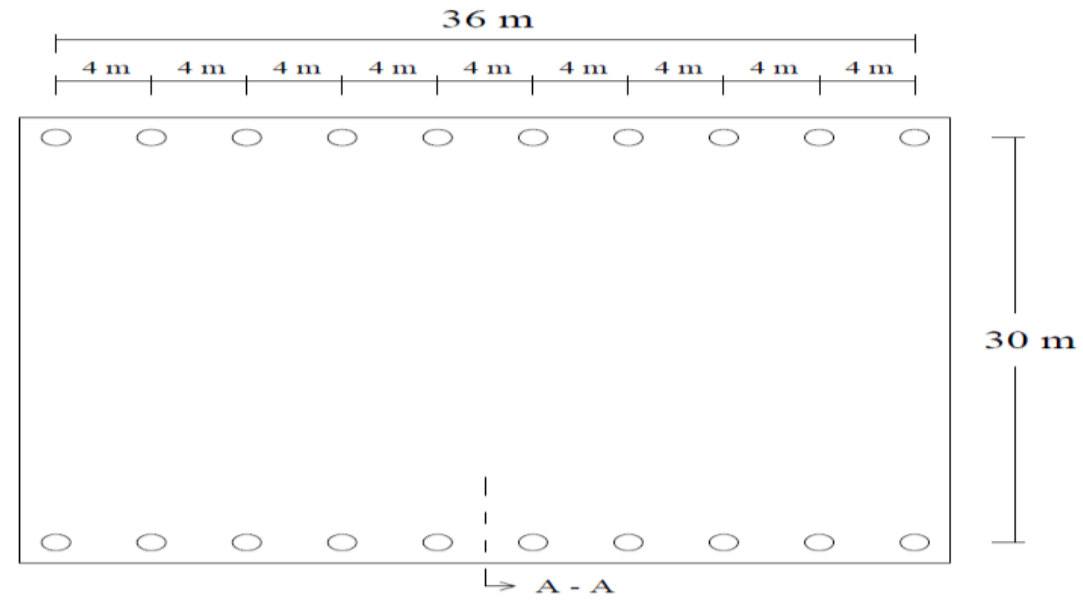

Sumber : Hasil Analisa 2020

Gambar 2. Denah konstruksi 
Doni Prayogi, M. Asmuni Jatoeb dan M. Nuklirullah, Perencanaan Struktur Atap RS Bhayangkara Polda Jambi Dengan Mempergunakan Profil Baja IWF

Sumber : Hasil Analisa 2020

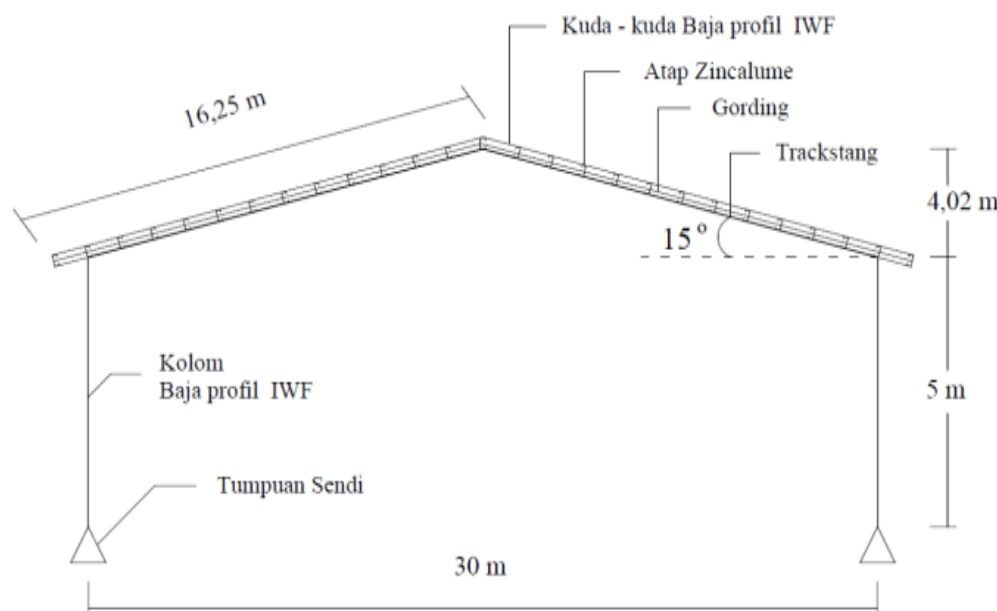

Gambar 3. Potongan A-A denah konstruksi

Tabel 2. Kombinasi gaya momen

\begin{tabular}{|c|c|c|c|c|c|c|c|c|c|c|}
\hline \multirow[b]{2}{*}{ TITIK } & \multirow[b]{2}{*}{$\begin{array}{c}\text { Frame } \\
\text { text }\end{array}$} & \multirow[b]{2}{*}{$\begin{array}{l}\text { Station } \\
\text { (m) }\end{array}$} & \multicolumn{4}{|c|}{ Momen } & \multicolumn{3}{|l|}{ Kombinasi } & \multirow[b]{2}{*}{$\begin{array}{c}\text { Nilai } \\
\text { Momen } \\
\text { Maks }\end{array}$} \\
\hline & & & $\begin{array}{l}\text { B. Mati (D) } \\
\text { (Kg.m) }\end{array}$ & $\begin{array}{l}\text { B. Hidup } \\
\text { (L) }(\text { Kg.m) }\end{array}$ & $\begin{array}{l}\text { B. Angin } \\
\mathrm{Kr}(\mathrm{Wkr}) \\
(\mathrm{Kg} \cdot \mathrm{m})\end{array}$ & $\begin{array}{c}\text { B. Angin } \\
\text { Kn (Wkn) } \\
(\mathrm{Kg} . \mathrm{m})\end{array}$ & $1,4 \mathrm{D}$ & $\begin{array}{c}1,2 \mathrm{D}+1,6 \mathrm{~L}+ \\
0,5 \mathrm{Wkr}\end{array}$ & $\begin{array}{c}1,2 \mathrm{D}+1,6 \mathrm{~L}+ \\
0,5 \mathrm{Wkn}\end{array}$ & \\
\hline \multirow{3}{*}{$A B$} & \multirow{3}{*}{$\begin{array}{c}\text { KOLOM } \\
\text { KIRI }\end{array}$} & 0 & 0 & 0 & 0 & 0 & 0 & 0 & 0 & \multirow{3}{*}{38780,34} \\
\hline & & 2,5 & 11961,94 & 2919,08 & $-947,19$ & 947,19 & 16746,716 & 18551,26 & 19498,45 & \\
\hline & & 5 & 23923,88 & 5838,16 & $-1461,25$ & 1461,25 & 33493,432 & 37319,09 & 38780,34 & \\
\hline \multirow{3}{*}{ DE } & \multirow{3}{*}{$\begin{array}{l}\text { KOLOM } \\
\text { KANAN }\end{array}$} & 0 & $-23923,88$ & $-5838,16$ & $-1461,25$ & 1461,25 & $-33493,43$ & $-38780,34$ & $-37319,09$ & \multirow{3}{*}{$-38780,34$} \\
\hline & & 2,5 & $-11961,94$ & $-2919,08$ & $-947,19$ & 947,19 & $-16746,72$ & $-19498,45$ & $-18551,26$ & \\
\hline & & 5 & 0 & 0 & 0 & 0 & 0 & 0 & 0 & \\
\hline \multirow{5}{*}{$B C$} & \multirow{5}{*}{$\begin{array}{c}\text { BALOK } \\
\text { KIRI }\end{array}$} & 0 & $-24229,22$ & $-5912,68$ & 1441,53 & $-1441,53$ & $-33920,91$ & $-37814,59$ & $-39256,12$ & \multirow{5}{*}{$-39256,12$} \\
\hline & & 3,88 & $-6646,83$ & $-1622,03$ & 1698,99 & $-1698,99$ & $-9305,562$ & $-9721,95$ & $-11420,94$ & \\
\hline & & 7,76 & 4564,30 & 1113,88 & 1545 & -1545 & 6390,02 & 8031,87 & 6486,87 & \\
\hline & & 11,64 & 9404,78 & 2295,06 & 979,56 & $-979,56$ & \begin{tabular}{|l|}
13166,692 \\
\end{tabular} & 15447,61 & 14468,05 & \\
\hline & & 15,53 & 7864,85 & 1919,27 & 0 & 0 & 11010,79 & 12508,65 & 12508,65 & \\
\hline \multirow{5}{*}{$C D$} & \multirow{5}{*}{$\begin{array}{l}\text { BALOK } \\
\text { KANAN }\end{array}$} & 0 & 7864,85 & 1919,27 & 0 & 0 & 11010,79 & 12508,65 & 12508,65 & \multirow{5}{*}{$-39256,15$} \\
\hline & & 3,88 & 9404,78 & 2295,27 & $-979,56$ & 979,56 & \begin{tabular}{|l|}
13166,692 \\
\end{tabular} & 14468,39 & 15447,95 & \\
\hline & & 7,76 & 4564,30 & 1113,88 & -1545 & 1545 & 6390,02 & 6486,87 & 8031,87 & \\
\hline & & 11,64 & $-6646,83$ & $-1622,03$ & $-1698,99$ & 1698,99 & $-9305,562$ & $-11420,94$ & $-9721,95$ & \\
\hline & & 15,53 & $-24229,22$ & $-5912,68$ & $-1441,59$ & 1441,59 & $-33920,91$ & $-39256,15$ & $-37814,56$ & \\
\hline
\end{tabular}

Sumber : Hasil Analisa 2020

Tabel 3. Kombinasi gaya geser

\begin{tabular}{|c|c|c|c|c|c|c|c|c|c|c|}
\hline \multirow[b]{2}{*}{ TITIK } & \multirow[b]{2}{*}{$\begin{array}{c}\text { Frame } \\
\text { text }\end{array}$} & \multirow[b]{2}{*}{$\begin{array}{l}\text { Station } \\
(\mathrm{m})\end{array}$} & \multicolumn{4}{|c|}{ Geser } & \multicolumn{3}{|c|}{ Kombinasi } & \multirow[b]{2}{*}{$\begin{array}{c}\text { Nilai Geser } \\
\text { Maks }\end{array}$} \\
\hline & & & $\begin{array}{l}\text { B. Mati (D) } \\
(\mathrm{Kg})\end{array}$ & $\begin{array}{l}\text { B. Hidup } \\
\text { (L) }\left(\mathrm{Kg}_{\mathrm{g}}\right)\end{array}$ & $\begin{array}{c}\text { B. Angin } \\
\mathrm{Kr}(\mathrm{Wkr}) \\
(\mathrm{Kg})\end{array}$ & $\begin{array}{c}\text { B. Angin } \\
\mathrm{Kn}(\mathrm{Wkn}) \\
(\mathrm{Kg})\end{array}$ & $1,4 \mathrm{D}$ & $\begin{array}{c}1,2 \mathrm{D}+1,6 \mathrm{~L}+ \\
0,5 \mathrm{Wkr}\end{array}$ & $\begin{array}{c}1,2 \mathrm{D}+1,6 \mathrm{~L}+ \\
0,5 \mathrm{Wkn}\end{array}$ & \\
\hline \multirow{3}{*}{$A B$} & \multirow{3}{*}{$\begin{array}{c}\text { KOLOM } \\
\text { KIRI }\end{array}$} & 0 & 4784,78 & \begin{tabular}{|l|}
1167,63 \\
\end{tabular} & $-465,5$ & 465,5 & 6698,692 & 7377,19 & 7842,69 & \multirow{3}{*}{7842,69} \\
\hline & & 2,5 & 4784,78 & 1167,63 & $-292,25$ & 292,25 & 6698,692 & 7463,82 & 7756,07 & \\
\hline & & 5 & 4784,78 & 1167,63 & -119 & 119 & 6698,692 & 7550,44 & 7669,44 & \\
\hline \multirow{3}{*}{$D E$} & \multirow{3}{*}{$\begin{array}{l}\text { KOLOM } \\
\text { KANAN }\end{array}$} & 0 & $-4784,78$ & $-1167,63$ & -119 & 119 & $-6698,692$ & $-7669,44$ & $-7550,44$ & \multirow{3}{*}{$-7842,69$} \\
\hline & & 2,5 & $-4784,78$ & $-1167,63$ & $-292,25$ & 292,25 & $-6698,692$ & $-7756,07$ & $-7463,82$ & \\
\hline & & 5 & $-4784,78$ & $-1167,63$ & $-465,5$ & 465,5 & $-6698,692$ & $-7842,69$ & $-7377,19$ & \\
\hline \multirow{5}{*}{$\mathrm{BC}$} & \multirow{5}{*}{$\begin{array}{c}\text { BALOK } \\
\text { KIRI }\end{array}$} & 0 & $-5117,7$ & $-1248,88$ & $-104,21$ & 104,21 & $-7164,78$ & $-8191,55$ & $-8087,34$ & \multirow{5}{*}{$-8191,55$} \\
\hline & & 3,88 & $-3592,19$ & $-876,6$ & $-5,69$ & 5,69 & $-5029,066$ & $-5716,03$ & $-5710,34$ & \\
\hline & & 7,76 & $-2066,67$ & $-504,33$ & 92,83 & $-92,83$ & $-2893,338$ & $-3240,52$ & $-3333,35$ & \\
\hline & & 11,64 & $-541,16$ & $-132,06$ & 191,34 & $-191,34$ & $-757,624$ & $-765,02$ & $-956,36$ & \\
\hline & & 15,53 & 984,36 & 240,21 & 289,86 & $-289,86$ & 1378,104 & 1710,50 & 1420,64 & \\
\hline \multirow{5}{*}{ CD } & \multirow{5}{*}{$\begin{array}{l}\text { BALOK } \\
\text { KANAN }\end{array}$} & 0 & $-984,36$ & $-240,21$ & 289,86 & $-289,86$ & $-1378,104$ & $-1420,64$ & $-1710,50$ & \multirow{5}{*}{8191,55} \\
\hline & & 3,88 & 541,16 & 132,06 & 191,34 & $-191,34$ & 757,624 & 956,36 & 765,02 & \\
\hline & & 7,76 & 2066,67 & 504,33 & 92,83 & $-92,83$ & 2893,338 & 3333,35 & 3240,52 & \\
\hline & & 11,64 & 3592,19 & 876,6 & $-5,69$ & 5,69 & 5029,066 & 5710,34 & 5716,03 & \\
\hline & & 15,53 & 5117,7 & 1248,88 & $-104,21$ & 104,21 & 7164,78 & 8087,34 & 8191,55 & \\
\hline
\end{tabular}

Sumber : Hasil Analisa 2020 
Doni Prayogi, M. Asmuni Jatoeb dan M. Nuklirullah, Perencanaan Struktur Atap RS Bhayangkara Polda Jambi Dengan Mempergunakan Profil Baja IWF

Tabel 4. Kombinasi gaya aksial

\begin{tabular}{|c|c|c|c|c|c|c|c|c|c|c|}
\hline \multirow[b]{2}{*}{ TITIK } & \multirow[b]{2}{*}{$\begin{array}{c}\text { Frame } \\
\text { text }\end{array}$} & \multirow[b]{2}{*}{$\begin{array}{l}\text { Station } \\
\text { (m) }\end{array}$} & \multicolumn{4}{|c|}{ Aksial } & \multicolumn{3}{|c|}{ Kombinasi } & \multirow[b]{2}{*}{$\begin{array}{l}\text { Nilai Aksial } \\
\text { Maks }\end{array}$} \\
\hline & & & $\begin{array}{l}\text { B. Mati (D) } \\
(\mathrm{Kg})\end{array}$ & $\begin{array}{l}\text { B. Hidup } \\
\text { (L) }(\mathrm{Kg})\end{array}$ & $\begin{array}{c}\text { B. Angin } \\
\mathrm{Kr} \text { (Wkr) } \\
(\mathrm{Kg})\end{array}$ & $\begin{array}{c}\text { B. Angin } \\
\mathrm{Kn}(\mathrm{Wkn}) \\
(\mathrm{Kg})\end{array}$ & $1,4 \mathrm{D}$ & $\begin{array}{c}1,2 \mathrm{D}+1,6 \mathrm{~L}+ \\
0,5 \mathrm{Wkr}\end{array}$ & $\begin{array}{c}1,2 \mathrm{D}+1,6 \mathrm{~L}+ \\
0,5 \mathrm{Wkn}\end{array}$ & \\
\hline \multirow{3}{*}{$A B$} & \multirow{3}{*}{$\begin{array}{l}\text { KOLOM } \\
\text { KIRI }\end{array}$} & 0 & $-7370,3$ & $-1798,58$ & $-126,99$ & 126,99 & $-10318,42$ & $-11785,58$ & $-11658,59$ & \multirow{3}{*}{$-11785,58$} \\
\hline & & 2,5 & $-7370,3$ & $-1798,58$ & $-126,99$ & 126,99 & $-10318,42$ & $-11785,58$ & $-11658,59$ & \\
\hline & & 5 & $-7370,3$ & $-1798,58$ & $-126,99$ & 126,99 & $-10318,42$ & $-11785,58$ & $-11658,59$ & \\
\hline \multirow{3}{*}{ DE } & \multirow{3}{*}{$\begin{array}{l}\text { KOLOM } \\
\text { KANAN }\end{array}$} & 0 & $-7370,3$ & $-1798,58$ & 126,99 & $-126,99$ & $-10318,42$ & $-11658,59$ & $-11785,58$ & \multirow{3}{*}{$-11785,58$} \\
\hline & & 2,5 & $-7370,3$ & $-1798,58$ & 126,99 & $-126,99$ & $-10318,42$ & $-11658,59$ & $-11785,58$ & \\
\hline & & 5 & $-7370,3$ & $-1798,58$ & 126,99 & $-126,99$ & $-10318,42$ & $-11658,59$ & $-11785,58$ & \\
\hline \multirow{5}{*}{$B C$} & \multirow{5}{*}{$\begin{array}{l}\text { BALOK } \\
\text { KIRI }\end{array}$} & 0 & $-6325,17$ & $-1543,54$ & 82,07 & $-82,07$ & $-8855,238$ & $-10018,83$ & $-10100,90$ & \multirow{5}{*}{$-10100,90$} \\
\hline & & 3,88 & $-5916,33$ & $-1443,77$ & 82,07 & $-82,07$ & $-8282,862$ & $-9368,59$ & $-9450,66$ & \\
\hline & & 7,76 & $-5507,50$ & -1344 & 82,07 & $-82,07$ & $-7710,5$ & $-8718,37$ & $-8800,44$ & \\
\hline & & 11,64 & $-5098,66$ & $-1244,23$ & 82,07 & $-82,07$ & $-7138,124$ & $-8068,13$ & $-8150,20$ & \\
\hline & & 15,53 & $-4689,82$ & $-1144,46$ & 82,07 & $-82,07$ & $-6565,748$ & $-7417,89$ & $-7499,96$ & \\
\hline \multirow{5}{*}{$C D$} & \multirow{5}{*}{$\begin{array}{l}\text { BALOK } \\
\text { KANAN }\end{array}$} & 0 & $-4689,82$ & $-1144,46$ & $-82,07$ & 82,07 & $-6565,748$ & $-7499,96$ & $-7417,89$ & \multirow{5}{*}{$-10100,97$} \\
\hline & & 3,88 & $-5098,66$ & $-1244,23$ & $-82,07$ & 82,07 & $-7138,124$ & $-8150,20$ & $-8068,13$ & \\
\hline & & 7,76 & $-5507,50$ & -1344 & $-82,07$ & 82,07 & $-7710,5$ & $-8800,44$ & $-8718,37$ & \\
\hline & & 11,64 & $-5916,33$ & $-1443,77$ & $-82,07$ & 82,07 & $-8282,862$ & $-9450,66$ & $-9368,59$ & \\
\hline & & 15,53 & $-6325,17$ & $-1543,58$ & $-82,07$ & 82,07 & $-8855,238$ & $-10100,97$ & $-10018,90$ & \\
\hline
\end{tabular}

Sumber : Hasil Analisa 2020

\section{Perhitungan Dimensi Balok - Kolom \\ Perhitungan dimensi balok}

Momen Maks pada balok

Gaya geser maks balok

$$
\begin{aligned}
& =39256,15 \mathrm{Kg} \cdot \mathrm{m} \\
& =8191,55 \mathrm{Kg} \\
& =10100,90 \mathrm{Kg}
\end{aligned}
$$

Gaya aksial maks balok

Mutu baja yang digunakan BJ 37 :

$f_{y} \quad=240 \mathrm{MPa}$

$f_{U} \quad=370 \mathrm{MPa}$

Digunakan untuk balok profil IWF $350 \times 350 \times 12 \times 19 \mathrm{~mm}$

1. Menghitung properti geometri penampang

$\mathrm{J}=1791089 \mathrm{~mm}^{4}$

$C_{w}=3,73 \times 10^{12} \mathrm{~mm}^{6}$

2. Kuat lentur penampang pada kondisi plastis (maksimum)

$Z_{X}=2493182 \mathrm{~mm}^{3}$

$\mathrm{M}_{\mathrm{p}}=59836,37 \mathrm{Kg} \cdot \mathrm{m}$

3. Tegangan kritis tekuk lentur

$$
\begin{aligned}
& \frac{\mathrm{KL}}{\mathrm{r}_{\min }}=\frac{1553 \mathrm{~cm}}{8,84 \mathrm{~cm}}=175,68>4,71 \sqrt{\frac{E}{F_{y}}}=135,97 \text { (Tekuk elastis) } \\
& F_{\text {e }}=63,89 \mathrm{MPa} \\
& F_{\text {cr }}=56,67 \mathrm{MPa}
\end{aligned}
$$

4. Tegangan kritis tekuk - puntir

$$
\begin{array}{ll}
\mathrm{G} & =77200 \mathrm{MPa} \\
G \times J & =1,38 \times 10^{11} \mathrm{~N} \cdot \mathrm{mm}^{2} \\
F_{\text {e }} & =313,04 \mathrm{MPa} \\
F_{\text {cr }} & =274,54 F_{y}
\end{array}
$$

5. Kuat tekan nominal kolom profil

$$
\begin{aligned}
& P_{n}=985539,67 \mathrm{~N} \\
& P_{C}=88698,57 \mathrm{Kg}
\end{aligned}
$$

6. Cek klasifikasi penampang

Profil simetri ganda $\mathrm{F}_{\mathrm{L}}=0,7 \mathrm{Fy}=168 \mathrm{MPa} K_{C}=0,78$

Sayap : $\lambda_{p f}=0,38\left(E / F_{y}\right)^{1 / 2}=10,97$ 
$\lambda_{r f}=0,95\left(K_{C} \times E / F_{L}\right)^{1 / 2}=25,07$

$\frac{1}{2} b_{f} / t_{f}=9,21<\lambda_{p f}=10,97<\lambda_{r f}=25,07$ (profil sayap kompak)

Badan : $\lambda_{p w}=3,76\left(E / F_{y}\right)^{1 / 2}=108,54$

$\lambda_{r w}=5,70\left(E / F_{y}\right)^{1 / 2}=164,54$

$h / t_{w}=26<\lambda_{p w}=108,54<\lambda_{r w}=164,54$ (profil badan kompak)

7. Parameter tekuk torsi lateral

$\mathrm{Lb}=5,17 \mathrm{~m} L_{p}=4,49 \mathrm{~m} L_{r}=17,13 \mathrm{~m}$

Momen nominal terhadap kondisi batas tekuk torsi lateral, untuk

$L_{p}=(2,31 \mathrm{~m})<L_{b}=(5,17 \mathrm{~m})<L_{r}=(6,87 \mathrm{~m})$

$\mathrm{M}_{\mathrm{n}}=1428358389 \mathrm{~N} \cdot \mathrm{mm}>\mathrm{M}_{\mathrm{p}}=598363680 \mathrm{~N} \cdot \mathrm{mm}$

Karena $M_{n}>M_{p}$ maka $M_{n}=M_{p}=598363680$ N.mm (tidak terjadi LTB)

8. Kuat lentur profil ditentukan oleh kondisi leleh

$\mathrm{M}_{\mathrm{nc}}=53852,73 \mathrm{Kg} \cdot \mathrm{m}$

$\phi \mathrm{M}_{\mathrm{n}}=88611,92 \mathrm{Kg} \cdot \mathrm{m}>\phi \mathrm{M}_{\mathrm{p}}=53852,73 \mathrm{Kg} \cdot \mathrm{m}$

Maka, $\phi \mathrm{M}_{\mathrm{n}}=53852,73 \mathrm{Kg} . \mathrm{m}$

9. Menghitung interaksi gaya aksial dan momen lentur

$\frac{P_{Y}}{P_{C}}=0,114<0,2$

$\frac{P_{r}}{2 P_{C}}+\left(\frac{M_{r x}}{M_{C x}}+\frac{M_{r y}}{M_{C y}}\right) \leq 1,0$

$0,06+\left(\frac{39256,15 \mathrm{Kg} \cdot \mathrm{m}}{53852,73 \mathrm{Kg} \cdot \mathrm{m}}+0\right) \leq 1,0$

$0,79 \leq 1,0(\mathrm{OK})$

10.Menghitung interaksi gaya geser dan momen lentur

$\phi \mathrm{V}_{\mathrm{n}}=544320 \mathrm{~N}$

$\frac{M_{U}}{\phi M_{n}}+0,625 \frac{V_{U}}{\phi V_{n}} \leq 1,375$

$\frac{39256,15 \mathrm{Kg} \cdot \mathrm{m}}{53852,73 \mathrm{Kg} \cdot \mathrm{m}}+0,625 \frac{8191,55 \mathrm{Kg}}{54432 \mathrm{Kg}} \leq 1,375$

$0,82 \leq 1,375(\mathrm{OK})$

\section{Perhitungan Dimensi Kolom}

Dari analisi dengan SAP 2000 didapatkan hasil sebagai berikut :

Momen maks pada kolom $(\mathrm{Mu})$

Gaya geser maks kolom $(\mathrm{Vu})$

$=38780,34 \mathrm{Kg} \cdot \mathrm{m}$

Gaya aksial maks kolom $(\mathrm{Pu})=(\mathrm{Pr})$

$=7842,69 \mathrm{Kg}$

Mutu baja yang digunakan BJ 37 :

$=11785,6 \mathrm{Kg}$

$f_{y}=240 \mathrm{MPa}$

$f_{U}=370 \mathrm{MPa}$

Digunakan untuk kolom profil IWF $350 \times 350 \times 12 \times 19 \mathrm{~mm}$

1. Menentukan klasifikasi penampang

Sayap : $\frac{b_{f}}{t_{f}}=\frac{35 \mathrm{~cm} \times 0,5}{1,9 \mathrm{~cm}}=9<\lambda_{r}=0,56 \sqrt{\frac{E}{F_{y}}}=16,17$ (tidak langsing)

Badan $: \frac{\hbar}{t_{w}}=\frac{31,2 \mathrm{~cm}}{1,2 \mathrm{~cm}}=26<\lambda_{r}=1,49 \sqrt{\frac{E}{F_{y}}}=43,01$ (tidak langsing)

2. Tegangan kritis tekuk lentur 


$$
\begin{aligned}
& \frac{\mathrm{KL}}{\mathrm{r}_{\text {min }}}=\frac{500 \mathrm{~cm}}{8,84 \mathrm{~cm}}=56,56<4,71 \sqrt{\frac{E}{F_{y}}}=135,97 \text { (Tekuk inelastis) } \\
& F_{\text {cr }}=0,85 F_{y}
\end{aligned}
$$

3. Tegangan kritis tekuk - puntir

$$
\begin{array}{lll}
\mathrm{G} & =77200 \mathrm{MPa} \\
G \times J & =1,38 \times 10^{11} \quad \text { N. } \mathrm{mm}^{2} \\
F_{\text {e }} & =801,66 \mathrm{MPa} \\
\frac{F_{y}}{F_{e}} & =0,30 \\
F_{\text {cr }} & =0,88 F_{y}
\end{array}
$$

4. Kuat tekan nominal kolom profil

$P_{n}=3545963,53 \mathrm{~N}$

$P_{C}=319136,72 \mathrm{Kg}$

5. Kuat lentur penampang pada kondisi plastis (maksimum)

$Z_{X}=2493182 \mathrm{~mm}^{3}$

$\mathrm{M}_{\mathrm{p}}=59836,37 \mathrm{Kg} \cdot \mathrm{m}$

6. Cek klasifikasi profil

Sayap : $\lambda_{p f}=0,38\left(E / F_{y}\right)^{1 / 2}=10,97 \lambda_{r f}=1,0\left(E / F_{y}\right)^{1 / 2}=28,87$

$\frac{1}{2} b_{f} / t_{f}=9<\lambda_{p f}=10,97<\lambda_{r f}=28,87$ (profil sayap kompak)

badan : $\lambda_{p w}=3,76\left(E / F_{y}\right)^{1 / 2}=108,54 \lambda_{r w}=5,70\left(E / F_{y}\right)^{1 / 2}=164,64$

$h / t_{w}=26<\lambda_{p w}=108,54<\lambda_{r w}=164,64$ (profil badan kompak)

7. Perhitungan akibat tekuk torsi lateral (LTB)

$(\mathrm{Lb})=5 \mathrm{~m} L_{p}=4,49 \mathrm{~m} L_{r}=17,13 \mathrm{~m}$

Momen nominal terhadap kondisi batas tekuk torsi lateral, untuk

$L_{p}=(4,49 \mathrm{~m})<L_{b}=(5 \mathrm{~m})<L_{r}=(13,72 \mathrm{~m})$

$\mathrm{M}_{\mathrm{n}}=981111890,3 \mathrm{~N} \cdot \mathrm{mm}>\mathrm{M}_{\mathrm{p}}=598363680 \mathrm{~N} . \mathrm{mm}$

Karena $\mathrm{M}_{\mathrm{n}}>\mathrm{M}_{\mathrm{p}}$ maka $\mathrm{M}_{\mathrm{n}}=\mathrm{M}_{\mathrm{p}}=598363680$ N.mm (tidak terjadi LTB)

8. Kuat lentur profil : ditentukan oleh kondisi leleh

$\mathrm{M}_{\mathrm{nc}}=53852,73 \mathrm{Kg} \cdot \mathrm{m}$

$\phi \mathrm{M}_{\mathrm{n}}=88611,92 \mathrm{Kg} \cdot \mathrm{m}>\phi \mathrm{M}_{\mathrm{p}}=53852,73 \mathrm{Kg} \cdot \mathrm{m}$

Maka, $\phi \mathrm{M}_{\mathrm{n}}=53852,73 \mathrm{Kg} . \mathrm{m}$

9. Menghitung interaksi gaya aksial dan momen lentur

$\frac{P_{Y}}{P_{C}}=\frac{11785,58 \mathrm{Kg}}{319136,72 \mathrm{Kg}}=0,04<0,2$

$\frac{P_{r}}{2 P_{C}}+\left(\frac{M_{r x}}{M_{C x}}+\frac{M_{r y}}{M_{C y}}\right) \leq 1,0$

$0,02+\left(\frac{38780,34 \mathrm{Kg} \cdot \mathrm{m}}{53852,73 \mathrm{Kg}, \mathrm{m}}+0\right) \leq 1,0$

$0,74 \leq 1,0(\mathrm{OK})$

10.Menghitung interaksi gaya geser dan momen lentur

$\phi \mathrm{V}_{\mathrm{n}}=544320 \mathrm{~N}$

$\frac{M_{U}}{\phi M_{n}}+0,625 \frac{V_{U}}{\phi V_{n}} \leq 1,375$

$\frac{38780,34 \mathrm{Kg} \cdot \mathrm{m}}{53852,73 \mathrm{Kg} \cdot \mathrm{m}}+0,625 \frac{7842,69 \mathrm{Kg}}{54432 \mathrm{Kg}} \leq 1,375$

$0,81 \leq 1,375(\mathrm{OK})$ 
Doni Prayogi, M. Asmuni Jatoeb dan M. Nuklirullah, Perencanaan Struktur Atap RS Bhayangkara Polda Jambi Dengan Mempergunakan Profil Baja IWF

\section{Perhitungan Sambungan}

\section{Sambungan balok dengan kolom}

Momen pada ujung balok yg disambung

Gaya geser pada ujung balok yg disambung $\left(\mathrm{R}_{\mathrm{u}}\right)$

Gaya aksial pada ujung balok yg disambung

$$
\begin{aligned}
& =39256,12 \mathrm{Kg} \cdot \mathrm{m} \\
& =8191,55 \mathrm{Kg} \\
& =10100,9 \mathrm{Kg}
\end{aligned}
$$

Persyaratan desain sambungan metode DFBK, di mana $\phi=0,75$

Profil baja balok ukuran $350 \times 350 \times 12 \times 19$

Mutu baja yang digunakan BJ 37 :

$f_{y}=240 \mathrm{MPa}$

$f_{U} \quad=370 \mathrm{MPa}$

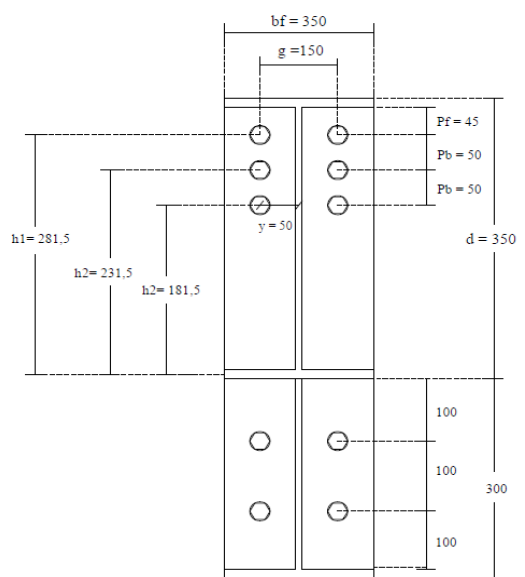

(a)

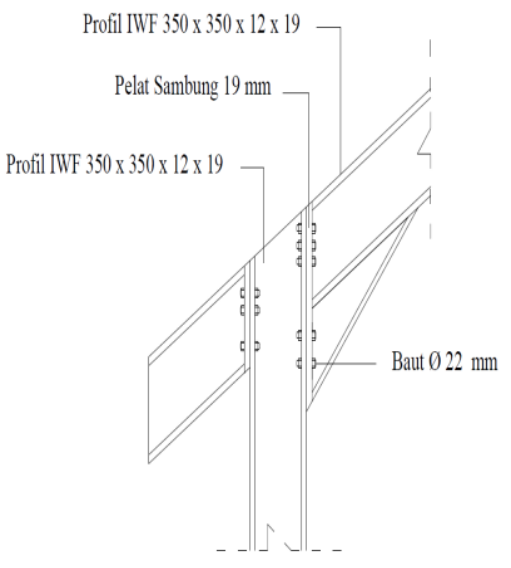

(b)

Gambar 4. Konfigurasi sambungan balok ke kolom (a) dan Detail sambungan balok ke kolom (b) Sumber : Hasil Analisa 2020

Jarak baut dari titik pusat lubang baut ke ujung tepi

$$
\begin{aligned}
1,5 \mathrm{~d} & \leq \mathrm{S}_{\mathrm{t}} \leq 12 \mathrm{t}_{\mathrm{p}} \\
1,5(22 \mathrm{~mm}) & \leq \mathrm{S}_{\mathrm{t}} \leq 12(19 \mathrm{~mm}) \\
33 \mathrm{~mm} & \leq \mathrm{S}_{\mathrm{t}} \leq 228 \mathrm{~mm} \\
& \mathrm{~S}_{\mathrm{t}}=50 \mathrm{~mm}
\end{aligned}
$$

Jarak antar baut

$$
\begin{aligned}
3 \mathrm{~d} & \leq \mathrm{S}_{\mathrm{t}} \leq 14 \mathrm{t}_{\mathrm{p}} \\
3(22 \mathrm{~mm}) & \leq \mathrm{S}_{\mathrm{t}} \leq 14(19 \mathrm{~mm}) \\
66 \mathrm{~mm} & \leq \mathrm{S}_{\mathrm{t}} \leq 266 \mathrm{~mm} \\
& \mathrm{~S}_{\mathrm{t}}=106 \mathrm{~mm}
\end{aligned}
$$

\section{Sambungan balok dengan balok}

Momen pada ujung balok yg disambung

Gaya geser pada ujung balok yg disambung

Gaya aksial pada ujung balok yg disambung

$$
\begin{aligned}
& =12508,65 \mathrm{Kg} \cdot \mathrm{m} \\
& =1710,5 \mathrm{Kg} \\
& =7499,96 \mathrm{Kg}
\end{aligned}
$$

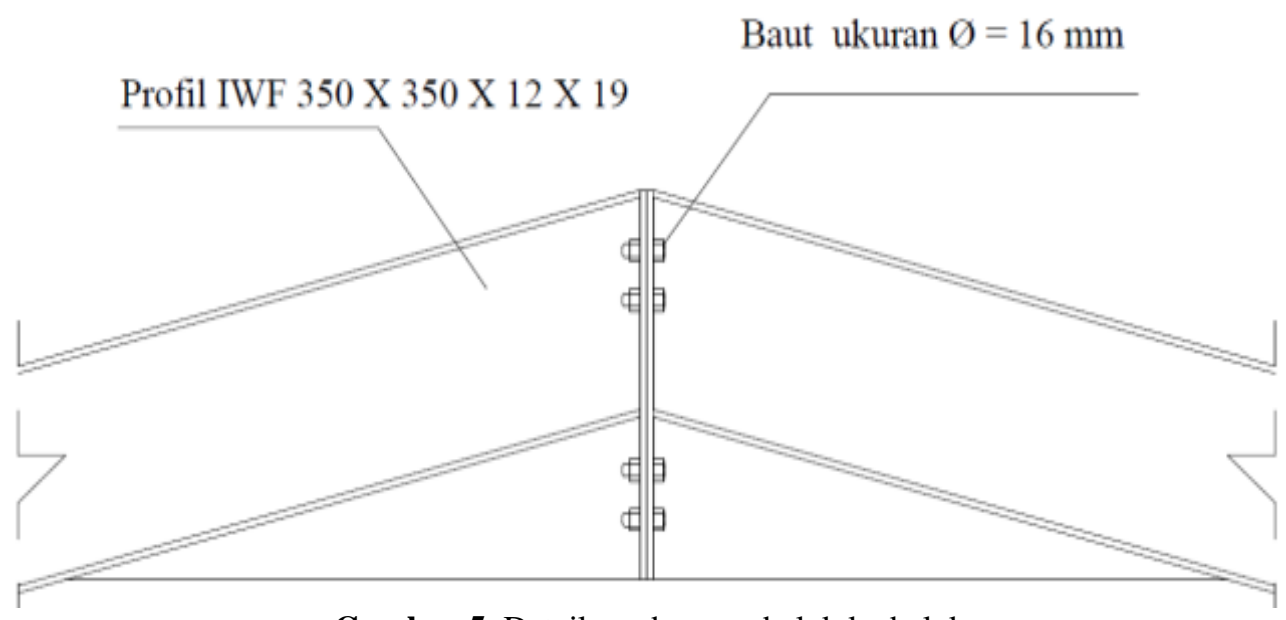

Sumber : Hasil Analisa 2020

Gambar 5. Detail sambungan balok ke balok 
Jarak baut dari titik pusat lubang baut ke ujung tepi

$$
\begin{array}{rlrl}
1,5 \mathrm{~d} & \leq \mathrm{S}_{\mathrm{t}} \leq 12 \mathrm{t}_{\mathrm{p}} & 3 \mathrm{~d} & \leq \mathrm{S}_{\mathrm{t}} \leq 14 \mathrm{t}_{\mathrm{p}} \\
1,5(16 \mathrm{~mm}) & \leq \mathrm{S}_{\mathrm{t}} \leq 12(19 \mathrm{~mm}) & 3(16 \mathrm{~mm}) \leq \mathrm{S}_{\mathrm{t}} \leq 14(19 \mathrm{~mm}) \\
24 \mathrm{~mm} & \leq \mathrm{S}_{\mathrm{t}} \leq 228 \mathrm{~mm} & 48 \mathrm{~mm} \leq \mathrm{S}_{\mathrm{t}} \leq 266 \mathrm{~mm} \\
& \mathrm{~S}_{\mathrm{t}}=50 \mathrm{~mm} & & \mathrm{~S}_{\mathrm{t}}=106 \mathrm{~mm}
\end{array}
$$

Sumber : Hasil Analisa 2020

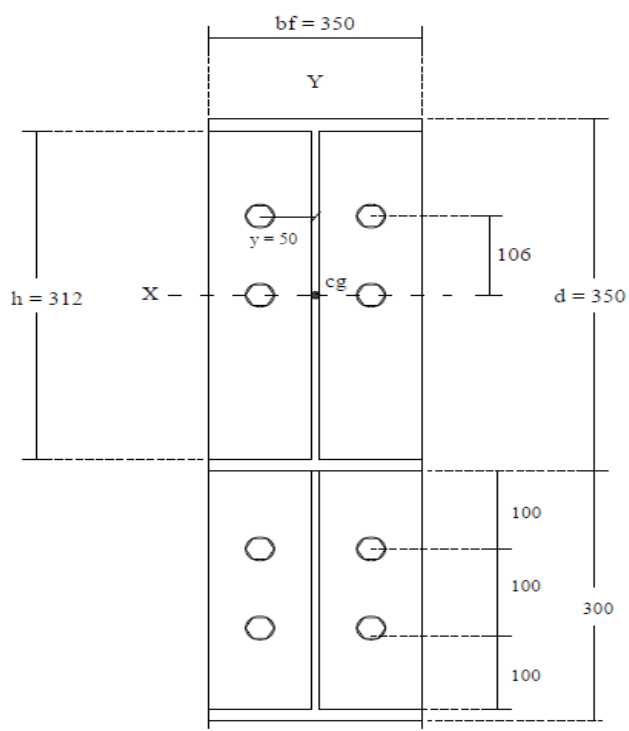

Gambar 6. Konfigurasi sambungan balok ke balok

\section{Sambungan Base-Plate}

Gaya aksial kolom $\left(\mathrm{P}_{\mathrm{u}}\right)=\left(\mathrm{N}_{\mathrm{ua}}\right)$

$$
\begin{aligned}
& =11785,58 \mathrm{Kg} \approx 117855,8 \mathrm{~N} \\
& =7842,69 \mathrm{Kg} \\
& =350 \mathrm{~mm} \\
& =450 \mathrm{~mm}
\end{aligned}
$$$$
\text { Gaya geser kolom }\left(\mathrm{V}_{\mathrm{ua}}\right)
$$

Panjang pelat bese-plate $(\mathrm{N})$

Baut angkur $\left(\mathrm{d}_{\mathrm{a}}\right) \phi 1$ in dan mutu A354 :

$f_{U}=862 \mathrm{MPa}$

Kedalaman baut angkur

$$
=300 \mathrm{~mm}
$$

Persyaratan desain baut angkur dengan metode DFBK dimana $\phi=0,75$

Digunakan pelat landas ukuran :

$\mathrm{B}=350 \mathrm{~mm}, \mathrm{~N}=400 \mathrm{~mm}, t_{P}=10 \mathrm{~mm}$

1. Kuat baut angkur terhadap tarik $\phi N_{s a}=13869,37 \mathrm{Kg}$

2. Kuat baut angkur kelompok terhadap geser $\left(V_{n}\right)$ Baut angkur kelompok $=43272,42 \mathrm{Kg}$

3. Interaksi gaya tarik dan gaya geser

Rasio gaya tarik

$\frac{\mathrm{N}_{\mathrm{ua}}}{\phi \mathrm{N}_{\mathrm{U}}}$

$$
=\frac{11785,55 \mathrm{Kg}}{13869,37 \mathrm{Kg}}=0,85
$$

Rasio gaya geser

$$
\frac{\mathrm{V}_{\text {ua }}}{\phi \mathrm{V}_{\mathrm{n}}}=\frac{7842,69 \mathrm{Kg}}{43272,42 \mathrm{Kg}}=0,18
$$

Cek interaksi

$\frac{\mathrm{N}_{\text {ua }}}{\phi \mathrm{N}_{\mathrm{U}}}+\frac{\mathrm{V}_{\text {ua }}}{\phi \mathrm{V}_{\mathrm{n}}}=1,03 \leq 1,2(\mathrm{OK})$ 
Doni Prayogi, M. Asmuni Jatoeb dan M. Nuklirullah, Perencanaan Struktur Atap RS Bhayangkara Polda Jambi Dengan Mempergunakan Profil Baja IWF

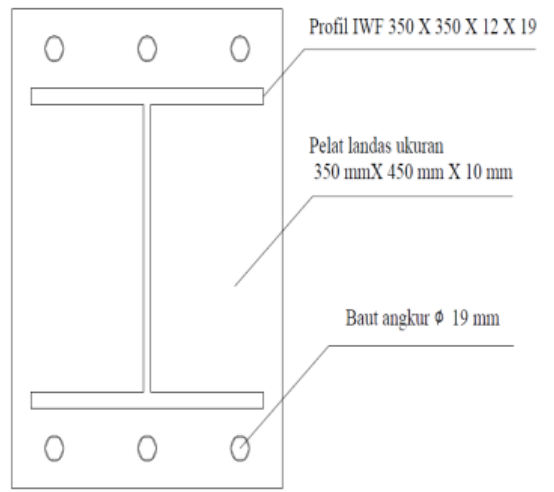

(a)

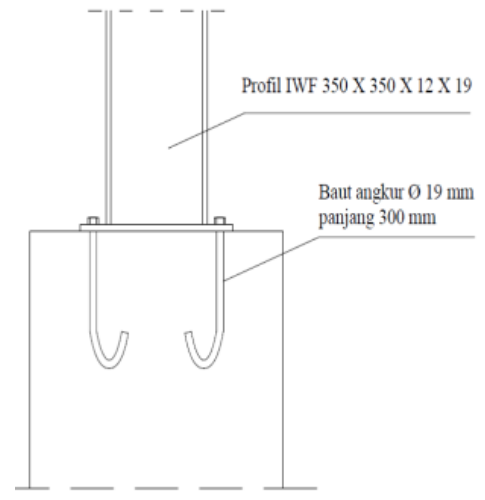

(b)

Gambar 7. Detail sambungan base - plate tampak atas (a) dan tampak samping (b)

Sumber : Hasil Analisa 2020

\section{Perhitungan sambungan las pada Base-plate}

Tebal pelat $\left(\mathrm{t}_{\mathrm{P}}\right)$

Ukuran las minimum

Ukuran las maksimum

Digunakan ukuran las

Digunakan las mutu E6013 :

kuat tarik $\left(F_{\text {ny }}\right)$

$$
\begin{aligned}
& =10 \mathrm{~mm} \\
& =5 \mathrm{~mm} \\
& =\mathrm{t}_{\mathrm{P}}-1,6 \quad=10 \mathrm{~mm}-1,6=8,4 \mathrm{~mm} \\
& =5 \mathrm{~mm}
\end{aligned}
$$$$
=450 \mathrm{MPa}
$$

1. Kuat rencana las sudut ukuran $5 \mathrm{~mm}$ per $\mathrm{mm}$ panjang $\phi \mathrm{R}_{\mathrm{nw}}=716,85 \mathrm{~N} / \mathrm{mm}$

2. Beban tarik terfaktor $\mathrm{R}_{\mathrm{u}}=117855,5 \mathrm{~N}+78426,9 \mathrm{~N}=196282,40 \mathrm{~N}$

3. Panjang perlu las sudut $\frac{\mathrm{R}_{\mathrm{u}}}{\phi \mathrm{R}_{\mathrm{n}}}=273,81 \mathrm{~mm} \approx 280 \mathrm{~mm}$

4. Cek tahanan nominal las $\phi_{w} \mathrm{R}_{\mathrm{n}} \geq \mathrm{R}_{\mathrm{u}}$ $716,85 \mathrm{~N} / \mathrm{mm}>\left(\frac{196282,40 \mathrm{~N}}{280 \mathrm{~mm}}=701,01 \mathrm{~N} / \mathrm{MM}\right)(\mathrm{OK})$

Sumber : Hasil Analisa 2020

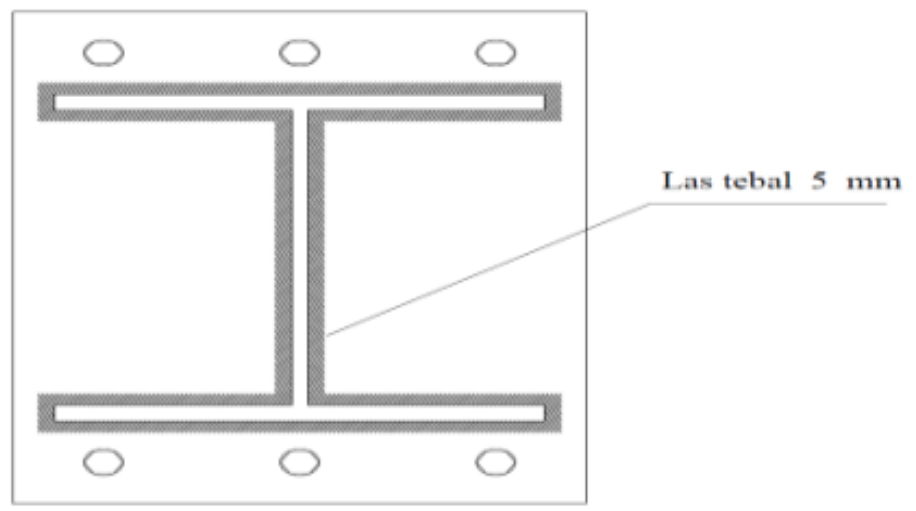

Gambar 8. Detail sambungan las base-plate

\section{SIMPULAN}

1. Dimensi balok menggunakan profil IWF ukuran $350 \times 350 \times 12 \times 19 \mathrm{~mm}$, dan untuk dimensi kolom menggunkan profil IWF ukuran $350 \times 350 \times 12 \times 19 \mathrm{~mm}$.

2. Sambungan konstruksi menggunakan baut dan las dengan hasil sebagai berikut : 
Doni Prayogi, M. Asmuni Jatoeb dan M. Nuklirullah, Perencanaan Struktur Atap RS Bhayangkara Polda Jambi Dengan Mempergunakan Profil Baja IWF

a. Sambungan balok dengan kolom menggunakan 10 baut $\emptyset 22 \mathrm{~mm}$ dan las ukuran $8 \mathrm{~mm}$ dengan panjang 160 mm.

b. Sambungan balok dengan balok menggunakan 8 baut $\emptyset 16 \mathrm{~mm}$ dan las ukuran $8 \mathrm{~mm}$ dengan panjang $90 \mathrm{~mm}$.

c. Sambungan base - plate menggunakan 6 baut angkur $\emptyset 19 \mathrm{~mm}$ dan las ukuran $5 \mathrm{~mm}$ dengan panjang $310 \mathrm{~mm}$.

\section{DAFTAR PUSTAKA}

Amon, Rene., Bruce Knobloch dan Atanu Mazumder. Perencanaan Konstruksi Baja Untuk Insinyur Dan Arsitek 1. Terjemahan oleh Ridwan Handoyo. Pradnya Paramita. Jakarta. 2000

Badan Standardisasi Nasional. Spesifikasi untuk bangunan gedung baja struktural. SNI 1729-2015. Jakarta. 2015

Badan Standardisasi Nasional. Beban minimum untuk perencanaan bangunan gedung dan struktural lain. SNI 17272013. Jakarta. 2013

Dewobroto, Wiryanto. 2016. Struktur Baja edisi kedua. Jurusan Teknik Sipil UPH. Tangerang. 2016

Oentoeng. Konstruksi Baja. ANDI. Yogyakarta. 2000

Setiawan, Agus. Perencanaan Struktur Baja dengan Metode LRFD. Erlangga. Semarang. 2008

Tamrin, A. G. Teknik Konstruksi Bangunan Gedung Jilid 2. Direktorat Pembinaan Sekolah Menengah Kejuruan. Jakarta. 2008 